\title{
Clinico Etiological Profile of Strabismic Amblyopia - An Observational Study
}

\author{
R. Prameela ${ }^{1}$, G. Sujatha ${ }^{2}$, B. N. Jayanthi ${ }^{3}$
}

\begin{abstract}
${ }^{1}$ Assistant Professor, Department of Ophthalmology, Osmania Medical College, Hyderabad, Telangana, India. ${ }^{2}$ Assistant Professor, Department of Ophthalmology, Osmania Medical College, Hyderabad, Telangana, India. ${ }^{3}$ Assistant Professor, Department of Ophthalmology, Osmania Medical College, Hyderabad, Telangana, India.
\end{abstract}

\section{ABSTRACT}

\section{BACKGROUND}

Amblyopia means "dullness of vision". There should be a minimum of 2 lines visual acuity fall on Snellen visual acuity chart compared with normal eye. Strabismic amblyopia is defined as amblyopia resulting from strabismic disorder without any other co-existing amblyogenic factors. It is assumed that $2-2.5 \%$ population has incidence of amblyopia. Amblyopia causes an important socioeconomic problem, especially in children, since the risk of the amblyopic patient becoming blind is significantly higher than in general population. Among all amblyogenic factors, strabismic disorder plays an important role. Since early diagnosis and proper treatment for eliminating causative factors of amblyopia like strabismus play a pivotal role in preventing in strabismic amblyopia, we wanted to determine the various etiological and clinical factors of strabismic amblyopia in children.

\section{METHODS}

This observational study was conducted among 135 cases of strabismic amblyopia, over a period of 1 year. Children in the age group of 4-15 years who were diagnosed as strabismic amblyopia after compressive ophthalmic examination, orthoptic evaluation, cycloplegic evaluation and fundus examination were included in the study. Data collected included age, sex, detailed history of delivery and consanguinity with regard to the onset of squint, type of deviations, duration of symptoms, family history of squint and usage of spectacles.

\section{RESULTS}

Out of 135 cases of strabismic amblyopia, 71 cases (53\%) were male and 64 cases $(47 \%)$ were female, esodeviations are more $(68 \%)$ than exodeviation $(16 \%)$, unilateral cases are more with large angle of deviations and some cases are associated with severe amblyopia. Stereopsis decreased in more number of cases with esodeviations and few eccentric fixation cases were also noted. All demographic, statistic, etiological and clinical features were statistically analysed and presented.

\section{CONCLUSIONS}

Amblyopia with large angle of esotropia is a common cause for strabismic amblyopia. Subjective visual and psychological functions are altered in these patients compared with normal population. With loss of binocularity, day by activity will be affected seriously and occupational hazards may occur during work. So, early detection and treatment is the key for the prevention of strabismic amblyopia.

\section{KEY WORDS}

Amblyopia, Strabismus, Visual Acuity, Esotropia, Exotropia, Stereopsis, Binocular Single Vision

\author{
Corresponding Author: \\ Dr. R. Prameela, \\ H. No. 6-3-249/6, \\ Flat No. 404, Alcazar Plaza \& Towers, \\ Roan No. 1, Banjara Hills, \\ Hyderabad-500034, Telangana, India. \\ E-mail:prameelar@yahoo.co.in
}

DOI: $10.14260 /$ jemds/2019/565

Financial or Other Competing Interests: None.

How to Cite This Article:

Prameela R, Sujatha G, Jayanthi BN. Clinico etiological profile of strabismic amblyopia an observational study. J. Evolution Med. Dent. Sci. 2019;8(33):2593-2596, DOI: $10.14260 /$ jemds $/ 2019 / 565$

Submission 25-12-2017,

Peer Review 20-02-2019,

Acceptance 28-02-2019,

Published 19-08-2019. 


\section{BACKGROUND}

Amblyopia is defined as a unilateral or bilateral decrease in visual acuity caused by form vision deprivation and abnormal binocular interaction for which no organic cause could be detected by the physical examination of the eye and which in appropriate cases is reversible by therapeutic measures. Amblyopia means "dullness of vision". There should be minimum 2 lines difference in visual acuity of two eyes.

It is assumed that $2-2.5 \%$ population has incidence of amblyopia. Amblyopia poses an important socioeconomic problem, especially in children, since the risk of the amblyopic patient becoming blind is significantly higher than in general population. The age at which children are most sensitive to amblyopia is during the first 2-4 years of life, and this sensitivity gradually decreases until the child reaches 6 or 7 years of age, when visual maturation is complete and the retinocortical pathways and visual centers develops and recognise the normal or abnormal visual inputs. This is the critical period for visual maturity. After 8-9 yr. of age plasticity of brain and visual pathway conduction mechanism decreases and active cortical inhibition if occurs then child develops permanent amblyopia. Strabismic amblyopia is caused when the two eyes are out of visual alignment and this is due to neuro muscular imbalance and motor dysfunction of extra ocular muscles and active cortical inhibition in the deviating eye leading to amblyopia in between ages of 2 to 4 years. Strabismus and amblyopia are common conditions in childhood, more at 5-10 years and it occurs in about $5 \%$ of 5 years old children with Esodeviations, exodeviations in association with hypertropia and abnormal head posture. Strabismic amblyopia is always unilateral and may be congenital or acquired in early childhood. Accommodative convergence squint develops in young children during the age of 2 to 3 years when the Child's intelligence demands more for near and this is associated with hypermetropia. A close habit of work may precipitate in convergent squint more so with accommodative esotropia In Strabismus, Consequent disuse of one eye and abnormal binocular interactions will arrest the development of visual acuity in children. Strabismus or amblyopia may lead to failure to develop binocular single vision which may prevent an individual in pursuing certain occupations. The associated cosmetic disorder may interfere with social and psychological development with potentially serious effects like psychosocial trauma in young patients. The above risk is high in developing country like India, where poverty, illiteracy and lack of Awareness are the additional factors.

We wanted to determine the clinico etiological profile of strabismic amblyopia in children, early diagnosis and proper treatment for eliminating causative factors of strabismic amblyopia at Sarojini Devi Eye Hospital, Hyderabad. Our study will determine the amblyopia in various types of Strabismus in paediatric age group.

\section{METHODS}

The observational study was conducted in 135 Strabismic amblyopia cases from Squint department of Sarojini Devi Eye Hospital, Hyderabad. Study period was one year from May2017 to April-2018. All the children in the age group of 4 to 15 years with strabismus were evaluated for the presence of amblyopia were included in the study with comprehensive ophthalmic examination and orthoptic evaluation after cycloplegic refraction and fundus examinations. A standardized case sheet proforma was filled out for each patient documenting full and detailed history with regard to the onset of squint, defective vision, duration of symptoms, history of delivery, consanguinity, family history of squint, usage of spectacles and previous history of amblyopia therapy.

\section{Inclusion Criteria}

Concomitant squint with various types in children between 415 years age, Visual acuity of - 2 lines difference in Snellen acuity chart.

\section{Exclusion Criteria}

1. Incomitant squint or paralytic squint.

2. Co-existing refractive errors and other amblyogenic factors are taken as exclusion criteria.

Every patient has received detailed examination for Assessment of Squint by Hirschberg's corneal reflex test, Krimskytest, Prism Bar cover test, cover-uncover test and Alternate cover test. Worth 4-dot test, Fixation behaviour, Stereopsis by Titmus fly stereo test. If necessary, the investigations like VEP test carried out and Clinical photos of previous and recent were also taken. General examination and any associated past illness and previous history for amblyopia treatment and noncompliance of occlusion therapy was noted. Children below the age of 5 years having esodeviations were atropinised for 3 days for cycloplegic refraction. For the children above 5 years advised with Cyclopentolate eye drops for dilatation and cycloplegic refraction. Esotropic children of less than 7 years were atropinised fully to relax accommodation and convergence during cycloplegic refraction. Recording of visual acuity with Pinhole, slit lamp examination, Fundus examination, Retinoscopy and AR reading with correction of glasses and prescription of glasses for illiterate children by E-chart and Lea symbol chart. For literate children with Snellen visual acuity chart followed by further treatment and management of functional vision therapy by occlusion of good eye according to age during this period was done.

All the cases were followed up for 6 months with periodic treatment in Sarojini Devi Eye Hospital, Hyderabad.

\section{RESULTS}

In the study, the following are the results for the total 135 selected cases reported with achieved details and test results are classified with various factors mentioned below in tabular 
format for the purpose to identify the risk factors for the causation of strabismic amblyopia. In our study of strabismic amblyopia- $68 \%$ of children have Esotropia, 16\% Exotropia, $3 \%$ vertical deviations and Esotropia or Exotropia associated with other congenital abnormalities noted $13 \%$.

\begin{tabular}{|c|c|}
\hline Male & Female \\
\hline 71 & 64 \\
\hline $53 \%$ & $47 \%$ \\
\hline \multicolumn{2}{|c|}{ Table 1. Sex Prevalence } \\
\hline $\begin{array}{l}\text { In our study of strabismic amblyopia cases presented more in male children 6\% than } \\
\text { female children. However, the gender difference is not high in percentage. }\end{array}$ \\
\hline
\end{tabular}
female children. However, the gender difference is not high in percentage.

\begin{tabular}{|c|c|c|}
\hline Age & Total Cases & $\mathbf{\%}$ \\
\hline <5 Years & 10 & $7 \%$ \\
\hline 5 to 8 years & 30 & $23 \%$ \\
\hline 8 to 10 Years & 44 & $33 \%$ \\
\hline 11 to 15 Years & 51 & $37 \%$ \\
\hline Esotropia & 92 Cases & $68 \%$ \\
\hline Exotropia & 22 Cases & $16 \%$ \\
\hline Vertical & 4 Cases & $3 \%$ \\
\hline $\begin{array}{c}\text { Other Congenital } \\
\text { Associations }\end{array}$ & 17 cases & $13 \%$ \\
\hline
\end{tabular}

Table 2. Age Distribution \& Types of Deviations

In our study with strabismic amblyopia the children in the age group of less than 5 years are $7 \%, 5-8$ years are $23 \%, 8-10$ years are $33 \%$ and $11-15$ years are $37 \%$.

\begin{tabular}{|c|c|c|c|c|c|c|c|c|}
\hline \multicolumn{3}{|c|}{ Mild } & \multicolumn{3}{|c|}{ Moderate } & \multicolumn{3}{|c|}{ Severe } \\
\hline \multicolumn{3}{|c|}{$6 / 12-6 / 24$} & \multicolumn{3}{|c|}{$6 / 24-6 / 60$} & \multicolumn{3}{|c|}{$>6 / 60$} \\
\hline \multicolumn{3}{|c|}{53} & \multicolumn{3}{|c|}{32} & \multicolumn{3}{|c|}{50} \\
\hline \multicolumn{3}{|c|}{$39.25 \%$} & \multicolumn{3}{|c|}{$23.75 \%$} & \multicolumn{3}{|c|}{$37 \%$} \\
\hline Eso & Exo & \begin{tabular}{|l|} 
Vertical \\
\end{tabular} & Eso & Exo & Vertical & Eso & Exo & Vertical \\
\hline 29 & 23 & 1 & 23 & 7 & \begin{tabular}{|l|}
2 \\
\end{tabular} & 31 & 18 & 1 \\
\hline $21 \%$ & $17 \%$ & $0.74 \%$ & $17 \%$ & $5.1 \%$ & $1.4 \%$ & $22 \%$ & $13 \%$ & $0.74 \%$ \\
\hline \multicolumn{9}{|c|}{$\begin{array}{l}\text { Table 3. Amblyopia Grading Depending on Visual Acuity \& } \\
\text { Grades of amblyopia in Various Types of Tropias }\end{array}$} \\
\hline $\begin{array}{l}\text { Jur stl } \\
\text { congen } \\
22 \%, 1\end{array}$ & $\begin{array}{l}\text { idy sho } \\
\text { ital ons } \\
7 \% \mathrm{mo}\end{array}$ & $\begin{array}{l}\text { ws not mu } \\
\text { et of Esotr } \\
\text { derate deg }\end{array}$ & $\begin{array}{l}\text { differen } \\
\text { ia. In es } \\
\text { and mil }\end{array}$ & $\begin{array}{l}\text { in grad } \\
\text { eviation } \\
\text { legree- }\end{array}$ & $\begin{array}{l}\text { es of amb } \\
1 \text { severe de } \\
21 \% \text { noted }\end{array}$ & $\begin{array}{l}\text { pia. Bu } \\
\text { ee of a }\end{array}$ & $\begin{array}{l}\text { oticed } r \\
\text { lyopia }\end{array}$ & $\begin{array}{l}\text { more with } \\
\text { noticed in }\end{array}$ \\
\hline
\end{tabular}

\begin{tabular}{|c|c|c|c|}
\hline & Unilateral & Alternating & $\mathbf{\%}$ \\
\hline Eso & 62 & 30 & 68 \\
\hline Exo & 8 & 14 & 16 \\
\hline Vertical & - & 4 & 4 \\
\hline Amblyopia 135 cases & Moderate to Severe RE 71 & $\begin{array}{c}\text { Mild to Moderate LE } \\
64\end{array}$ & \\
\hline
\end{tabular}

Table 4. Laterality of Strabismus and amblyopia

Strabismic Amblyopic cases are more in unilateral Esodeviations - 62 (68\%) cases out of total 92 cases of Esodeviations and moderate to severe amblyopia type of cases are seen in right eye $-71(53 \%)$ cases and in left eye $64(47 \%)$ cases of Mild to moderate amblyopia cases are seen.

\begin{tabular}{|c|c|c|}
\hline Stereopsis & Eso & Exo \\
\hline Present & 3 & 10 \\
\hline Decreased & 80 & 34 \\
\hline Table 5. Binocular Single Vision- Titmus Fly Test with Butterfly (3600 \\
arc of sec.):
\end{tabular}

\begin{tabular}{|l|c|c|}
\hline \multicolumn{1}{|c|}{ Central } & Eso & Exo \\
\hline & 5 & 1 \\
\hline 129 Cases & Table 6. Fixation Pattern \\
\hline \multicolumn{2}{|c|}{} \\
\hline $\begin{array}{l}\text { Excentric fixation is present in large angle congenital esotropia } 5 \text { cases and } 1 \text { case-of } \\
\text { Exotro is noticed. }\end{array}$
\end{tabular}

\begin{tabular}{|c|c|c|c|}
\hline PBCT & Total Cases & Eso & Exo \\
\hline $30-45 \Delta$ & 35 & 20 & 15 \\
\hline$>45 \Delta$ & 96 & 73 & 23 \\
\hline \multicolumn{3}{|c|}{ Table 7. Angle of Deviation with PBCT } \\
\hline
\end{tabular}

In Esotropia associated with amblyopia- large angle of deviations are seen in73 cases (76\%) i.e.in total of 96 cases and exotropia cases are $23(17 \%)$.

\begin{tabular}{|c|c|c|}
\hline Family History & 36 & $26 \%$ \\
\hline Consanguinity & 23 & $17 \%$ \\
\hline Table 8. Role of Heredity \\
\hline In the study Role of heredity show positive reports in 59 cases of Strabismic \\
amblyopia i.e., 43\%. \\
\hline
\end{tabular}

\begin{tabular}{|c|c|c|}
\hline Premature Birth/ Low Birth Weight & 12 & $8.8 \%$ \\
\hline Delayed Milestones & 14 & $10.0 \%$ \\
\hline Maternal Illness & 4 & $2.9 \%$ \\
\hline Convulsions/ Cerebral Palsy & 4 & $2.9 \%$ \\
\hline Nystagmus & 2 & $1.1 \%$ \\
\hline Table 9. Other Congenital Associations \\
\hline $\begin{array}{l}\text { In our study of Strabismic amblyopia prematurity with low birth weight and delayed } \\
\text { milestones associated with other congenital disorders are noticed in some cases. }\end{array}$ \\
\hline
\end{tabular}

\section{DISCUSSION}

Gender difference is not prominently noticed in our study. Out of 135 cases of Strabismic amblyopia sex prevalence is 71 male and 64 female children and age prevalence is Above 5 years, and esodeviations are more-(68\%) than exotropia $(16 \%)$, unilateral cases are more with large angle of deviations and severe amblyopia. Stereopsis decreased in more number of cases with Esodeviations and with few eccentric fixations. Demographic, statistic, etiological and clinical features are statistically analysed and presented in the study.

In this study male children with strabismic amblyopia cases are $6 \%$ more than female children, though the gender difference is not much high. As per Kimberly et al, study there is no gender difference in strabismic amblyopia.[1] As per Burian-von Noorden's; [2] Strabismic amblyopia is common in children of 5-10 years age. Same results are reported in our study. In this study prevalence of age groups are more at the ages of 5-10 years [56\%] and 7\% cases are seen up to 5 years of age. In another study by Royal College of Ophthalmologists, ${ }^{[3]}$ amblyopia is common conditions in childhood, with strabismus affecting about $5 \%$ of five-year olds of whom $60 \%$ have esodeviations and $20 \%$ exodeviations. Amblyopia has an estimated prevalence in childhood of $1.2 \%$ to $4.4 \%$. Same as above study our study shows Prevalence of Strabismic amblyopia is more in Eso deviation than Exodeviation with ratio of $68 \%$ of Esodeviations and 16\% of Exodeviations and 3\% of vertical deviations, Eso and Exo associated with other anomalies are $13 \%$. In the article of amblyopia -by Kimberly G. Yen[1] study shows $-60 \%$ of Eso deviations and $20 \%$ of Exo deviation. In another study by Neepa Thacker[4] says -Internationally Esodeviations are more frequent than exodeviations, with a ratio of 3:1.

We have also observed severe degree of amblyopia which is more in long standing Eso deviations and less frequently seen in Exo deviations. According to studies like PEDIG; [Paediatric eye diseases investigator study group] and ATS; [Amblyopia treatment studies] amblyopia has been graded into mild, moderate and severe degree of amblyopia. In this clinical study we have observed that there is no difference in right or left eye presentation for fixation. Same has been observed by Burian-von Noorden's: ${ }^{[2]}$ as There is no preference to right or left Eyes. In our study strabismic amblyopia cases without refractive error are $83 \%$ and with refractive error like Anisometropic Strabismus cases are $13.2 \%$ seen. A study by Klin Oczna $-2004 ;$; $^{[5]}$ shows similar incidences like our study, $57 \%$ of Strabismic amblyopia cases are without refractive error and $27 \%$ of Strabismic amblyopia cases are with refractive error.

We have also observed on Role of heredity, [Family history and Consanguinity] 43\%, neurological disorders, prematurity, delayed milestones, convulsions and Nystagmus are $26 \%$. It was noticed that they play an important role in 
association with strabismus and amblyopia. As per the study by Govind Amita, et al,[6] Seventy children with cerebral palsy were examined for etiological factors responsible, type of disorder and ocular abnormalities. The overall incidence of ocular abnormalities were $69 \%$, the highest frequency being of squint $(35.7 \%)$. Other anomalies detected included refractive errors (28.5\%), optic atrophy (10\%) and coloboma (2.9\%). These patients usually have associated mental sub normality $(50 \%)$, emotional instability and convulsive disorders (25\%). The article by Demer JL, et al[7] says, Strabismic amblyopia associated with DVD and Horizontal deviations are seen in some cases with congenital anomalies. Horizontal and Vertical deviations are combined, and slight restriction of the movement is noted. The following points were also observed during our study of Strabismic amblyopia- unilateral cases of Strabismic amblyopia with large angles are more in congenital Eso deviations and alternating cases are noticed more in Exo deviation [8]. Patients with Strabismus who strongly favour one eye for fixation and who have a unilateral rather than an alternating fixation are mostly likely to developing Strabismic amblyopia at the age of 3 years and above. Crowding phenomenon more enhanced and contrast sensitivity is decreased in strabismic amblyopia type of cases. In Severe Strabismic amblyopia cases with eccentric fixation leading to loss of the ability for form vision discrimination and stereopsis. Presence of free alternation indicates almost equal visual acuity in both eyes. In cases of Strabismic amblyopia no alternate fixation indicates suppression amblyopia developed in one eye. Strabismic amblyopia cases have shown changes in VEP pattern like latencies are prolonged and amplitudes are decreased in 22 cases. In our study we also observed children presented with ocular problems are more in paediatric department in early childhood with congenital anomalies like congenital esotropia, refractive errors and nystagmus are leading risk factors to amblyopia. So for this, there is a need for Eye related health care infrastructures particularly on children vision screening programs to be established at every District headquarters focusing mainly at rural and urban areas under Govt. sectors and also school health programs with the help of trained ophthalmic assistants/NGOs along with voluntary organizations to screen the children under 5 years followed by treatment (like amblyopia therapy and strabismus surgery of the rectus muscles; ${ }^{[9]}$ ) compulsory because children are the future of the nation for which their eye related health care is very much essential. Finally, public awareness and Education of parents about squint and its complications is important for prevention of further damage of visual acuity in children. So, with this, we can avoid the Avoidable Blindness in country.

Squint doesn't bring Good luck in individuals; it causes problems in future like occupational hazards in workplace and psychosocial trauma to the individual due to loss of binocularity and deviations.

\section{CONCLUSIONS}

Strabismus with large angle of esotropia associated with amblyopia is a common cause of strabismic amblyopia and its persistence in childhood is a significant risk factor for an individual for losing sight silently in the fellow eye. Timely diagnosis and appropriate intervention in children with strabismus with amblyopia is the key to reduce the prevalence of amblyopia and ocular misalignment. Prevention is better than the cure. In this study children presented late, with deep seated amblyopia after the plastic or critical period, because of lack of awareness among parents, family physician and paediatrician. So, our main aim is to create awareness in parents, the public.

\section{REFERENCES}

[1] Kimberly G, Yen MD. Strabismic amblyopia. Updated 20 July, 2018. https://emedicine.medscape.com/article/1214603

[2] Borden JA. Burian-von Noorden's Binocular vision and ocular motility. Theory and Management of Strabismus. Yale J Biol Med 1986;59(1):73-4.

[3] Royal College of Ophthalmologists. (2000). Guidelines for the Management of Strabismus and amblyopia in Childhood. ww.mrcopnth.com/focus1/strabismus.htm Accessed February 2000).

[4] Thacker N. Acquired exotropia. Updated: 15 Nov, 2018. https://emedicine.medscape.com/article/1199004.

[5] Szaflik J, Prost M, Zaleska-Zmijewska A, et al. The analysis of refractive error in children and adolescents from 6-15 years of age based on 1000 examinations in two major Polish regions. Klin Oczna 2004;106(Suppl 3):471-3.

[6] Govind A, Lamba PA. Visual disorders in cerebral palsy. Indian J Ophthalmol 1988;36(2):88-91.

[7] Demer JL, Zee DS. Vestibulo-ocular and optokinetic deficits in albinos with congenital nystagmus. Invest Ophthalmol Vis Sci 1984;25(6):739-45.

[8] Helveston EM. 19th annual Frank Costenbader Lecturethe origins of congenital esotropia. J Pediatr Ophthalmol Strabismus 1993;30(4):215-32.

[9] Von Noorden GK. The limbal approach to surgery of the rectus muscles. Arch Ophthalmol 1968;80(1):94-7. 